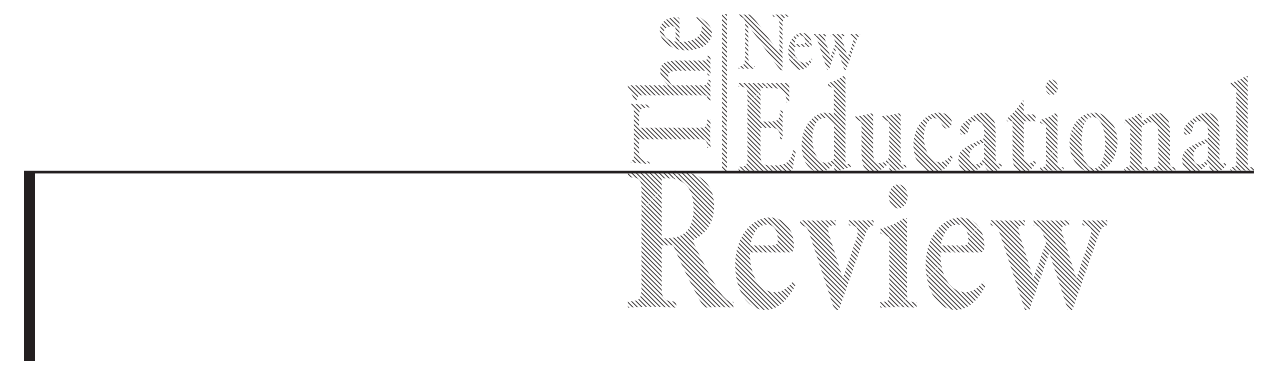

\title{
Reviewers of the Manuscripts Sent from Poland and from the Whole World to "The New Educational Review" in 2015
}

DOI: 10.15804/tner.2015.42.4.27

Prof. PhD. Amantius Akimjak

PhDr. Radim Badošek, Ph.D.

Dr hab. Ewa Bielska

Dr hab. Maciej Bernasiewicz

Dr hab. Katarzyna Borzucka-Sitkiewicz

Dr Anna Brosch

PhDr. Martin Chvál, Ph.D.

Prof. PhD. Estera Czoj

prof. PaedDr. Alena Doušková, PhD.

Dr Monika Frania

prof. PhDr. Eva Gajdošová, PhD.

Dr hab. Alicja Gałązka

Prof. dr hab. Małgorzata Górnik-Durose

doc. PaedDr. Ctibor Határ, PhD.

Prof. PhD. Yaomin He

prof. PhDr. Jolana Hroncová, PhD.

prof. PaedDr. Anna Hudecová, PhD.

Dr Tomasz Huk

Prof. PhD. Tomaš Jablonsky

Prof. zw. dr hab. Stanisław Juszczyk

prof. PhDr. Soňa Kariková, PhD.

prof. PhDr. Bronislava Kasáčová, CSc.

Prof. PhD. YongDeog Kim

Dr hab. Mirosław Kisiel

Prof. PhD. Alojz Kostelansky 
Doc. PaedDr. Soňa Kotátková, Ph.D.

Prof. dr hab. Katarzyna Krasoń

prof. PhDr. Blahoslav Kraus, CSc.

RNDr. Krpec, Ph.D.

Prof. PhD. Viera Kurincová

Prof. zw. dr hab. Barbara Kożusznik

Mgr. Hana Kubíčková, Ph.D.

Prof. zw. dr hab. Stefan M. Kwiatkowski

PhDr. Lucia Lacková, Ph.D.

Prof. zw. dr hab. Eugenia Mandal

Prof. PhD. Katsuhiko Matsukawa

prof. PhDr. Erich Mistrík, CSc.

Prof. RNDr. Josef Molnár, CSc.

Dr Monika Noszczyk-Bernasiewicz

Prof. PhD. Erich Petlák

Doc. PhDr. Alena Petrová, Ph.D.

Dr hab. Beata Pituła

Doc. PhDr. Irena Plevová, Ph.D.

doc. PaedDr. Štefan Porubský, PhD.

Dr hab. Danuta Rode

doc. PhDr. Vladimír Salbot, CSc.

Prof. zw. dr hab. Bronisław Siemieniecki

Doc. PhDr. Alena Slezáčková Ph.D.

Doc. PhDr. Irena Sobotková, Ph.D.

Prof. zw. dr hab. Jerzy Stochmiałek

Mgr. Anna Ševčíková, Ph.D.

Doc. PhDr. Eva Šmelová, Ph.D.

Prof. dr hab. Maciej Tanaś

Prof. zw. dr hab. Andrzej Radziewicz-Winnicki

Prof. PhD. Peter Seidler

Prof. zw. dr hab. Adam Stankowski

doc. PhDr. Zlata Vašašová, PhD.

Dr Anna Waligóra-Huk

Dr hab. Ewa Wysocka

Dr.h.c. prof. PhDr. Miron Zelina, DrSc. 